\title{
Viability trade-offs in the evaluation of strategies to manage recreational fishing in a marine park
}

\author{
Olivier Thébaudd ${ }^{a, b, d,{ }^{*}, \text { Nick Ellis }}{ }^{a, b}$, L. Richard Little ${ }^{c, b}$, Luc Doyen ${ }^{e}$, Ross J. Marriott ${ }^{\dagger}$
}

\author{
${ }^{a}$ CSIRO Marine \& Atmospheric Research, 41 Boggo Rd., Dutton Park, QLD 4102, Australia \\ ${ }^{\mathrm{b}}$ CSIRO Wealth from Oceans Flagship, Centre for Environment \& Life Sciences, Underwood Avenue, Floreat \\ Park, WA 6014, Australia \\ ${ }^{c}$ CSIRO Marine and Atmospheric Research, Castray Esplanade, Hobart, TAS 7000, Australia \\ d Ifremer, UMR M101, AMURE, Unité d'Economie Maritime, BP 70, F-29280 Plouzané Cedex, France \\ e CNRS, GREThA, University of Bordeaux IV, Avenue Léon Duguit, 33608 Pessac cedex, France \\ ${ }^{f}$ Department of Fisheries of Western Australia, Research Laboratories, PO Box 20, North Beach, WA 6920, \\ Australia
}

\author{
*: Corresponding author : Olivier Thébaud, tel.: +332 98224989 ; email address : olivier.thebaud@ifremer.fr \\ nick.ellis@csiro.au ; rich.little@csiro.au ; luc.doyen@u-bordeaux4.fr ; ross.marriott@fish.wa.gov.au
}

\begin{abstract}
:
Management strategy evaluation (MSE) is an analytical process used to evaluate alternative strategies for the management of renewable resource systems against explicitly stated objectives using a dynamic simulation framework. A key pre-requisite of MSE involves turning broad conceptual objectives into quantifiable and measurable operational objectives, against which the performance of management strategies can be assessed in simulations. However, given the large uncertainty typical of many renewable resource management problems and the potential diversity of stakeholder interests and needs, specification of operational management objectives for MSE often proves a challenge.

In this article, a new approach to the evaluation of multidimensional outputs from MSE modeling, taking into account uncertainty regarding the reference levels of performance indicators (PIs) is proposed. The approach uses the notion of viable management strategies, as defined in recent applications of viable control to marine social-ecological systems, to examine the way in which simulated operational management objectives can be set. In this context, "viable" management strategies are defined as those which allow reference levels for candidate Pls to be met at some preagreed levels of tolerance, and we consider the possibility for these reference levels to be uncertain.
\end{abstract}

The approach is applied to the multidimensional set of results from an MSE study conducted on recreational fishing for spangled emperor (Lethrinus nebulosus) in the Ningaloo Marine Park of Western Australia. The analysis shows how the complexities in management arrangements on recreational fishing, combining spatial management restrictions on fishing as well as conventional fisheries management regulations, which the MSE model accounted for in a multidimensional set of simulation results, can be synthesized using viability analysis. Results point to the existence of management options which provide greater "room to move", in setting reference and tolerance levels, for the range of objectives identified by stakeholders. Beyond the application to Ningaloo Reef, the approach could be transferrable to any other simulation-based outcomes of MSE for natural resource systems, both marine and land-based. 


\section{Highlights}

- We propose an approach to specifying operational resource management objectives. Viability analysis is used to assess multidimensional outputs of a management model. D Strategies allowing greater room to move in setting reference levels are identified. The approach is applied to the management of recreational fishing in a marine park.

Keywords: Management strategy evaluation ; Multiple objectives ; Viability analysis ; Ecologicaleconomic modeling ; Recreational fishing ; Ningaloo Marine Park (Western Australia) 


\section{Introduction}

Management Strategy Evaluation (MSE) is gaining recognition as a useful approach to assist in the adaptive management of natural resource use (Smith 1994, Sainsbury et al. 2000, Smith et al. 2007, Dichmont et al. 2008, Butterworth et al. 2010, Bunnefeld et al. 2011). It has been largely applied to marine fisheries, and is increasingly considered as a promising approach in the broader context of managing multiple uses. Management Strategy Evaluation is an analytical process used to test alternative management strategies in simulation space before implementing them in reality. Interactions between renewable resource systems, their observation and assessment, decision rules and implementation of management decisions are typically incorporated into these simulation exercises. A range of pre-identified scenarios regarding external influences, such as climate change, technological creep or changing infrastructure can also be accounted for in projecting and evaluating the potential effectiveness of candidate management strategies (Little et al. 2011). The resulting simulated outcomes are then compared with pre-specified objectives, in order to elicit preferred control strategies (Dichmont et al. 2008, Mapstone et al. 2008, Dichmont et al. 2010, Bunnefeld et al. 2011).

A key pre-requisite to the implementation of a MSE is turning what are usually broad management objectives into operational objectives against which the performance of management strategies can be measured in quantitative terms (Sainsbury et al. 2000). The specification of such operational management objectives requires three key elements: (i) identifying a performance indicator (PI) associated with each objective, (ii) defining reference levels (e.g. targets, thresholds or limits) for each indicator to reflect whether the objective is achieved, and (iii) identifying the tolerance limits for the indicators, that represent the degree of uncertainty associated with meeting the objective (Boschetti et al. 2010).

The process of specifying such operational management objectives has increasingly involved participation from stakeholders (Mapstone et al. 2008, Holland 2010), including for example representatives of recreational and commercial fishing groups as well as conservation groups and management agencies. It has been suggested that stakeholder participation is critical to ensure that MSE simulations will be relevant and result in useful information regarding management options (Sainsbury et al. 2000). More generally, a growing literature has emphasized the potential role for, and challenges of, participatory simulation modeling in natural resources management (d'Aquino et al. 2002, Hare et al. 2003, Jones et al. 2007, Voinov and Gaddis 2008, Boschetti et al. 2010, Boschetti et al. 2012). Having a wide range of stakeholder groups involved in the process of setting objectives, Pls and reference levels for MSE typically results in a diverse range of targets for simulated management strategies and, accordingly, a complex set of results for interpretation (e.g., Mapstone et al., 2008, Little et al. 2011).

Methods and tools supporting the identification of operational management objectives thus have a crucial role to play in MSE, particularly if they can help stakeholders reach agreement on the identification of such objectives. This is particularly true in cases where management must consider multiple objectives, which is commonly encountered in the multiple-use management settings in which MSE approaches are increasingly being applied.

This article proposes a method to assist in identifying operational management objectives for marine resource management for MSE. We develop an approach that allows systematic evaluation of the outcomes of a set of simulated strategies and scenarios against multiple objectives as identified by stakeholder groups. We use the notion of viable management strategies, as defined in recent applications of viability theory to the dynamic control of marine social-ecological systems (Béné et al. 2001, Eisenack et al. 2006, De Lara et al. 2007, Martinet et 
al. 2007, Doyen et al. 2012, Pereau et al. 2012) to examine the way in which operational management objectives can be set for a fishery modeled as a stochastic dynamic system. In particular, we explore the ability of a range of management strategies to achieve competing objectives, with changes in the Pls with respect to reference levels and tolerance measures used to assess the extent to which management objectives are being met.

The approach is applied to results of a MSE study conducted on recreational fishing for spangled emperor (Lethrinus nebulosus), in the Ningaloo Marine Park of Western Australia (Little et al. 2011). Spangled emperor is one of a wide range of species targeted by recreational fishers in the Marine Park and was selected as the focal species of that study. The study examined alternative management options against a set of stakeholder-defined operational objectives. The MSE model that was developed was demonstrated to be a useful tool in accounting for the complexities in management arrangements on recreational fishing, due to the combination of both spatial management restrictions on fishing as well as conventional fisheries management regulations in the Marine Park. Here we show how these complexities, borne out in the multidimensional set of simulation results, can be synthesized using viability analysis.

\section{Methods}

We first of all set out the general framework for defining and computing viability for management strategies. We then apply this framework to the MSE case study.

\subsection{General framework}

We consider a harvested biological resource described by a set of biomass-dynamic equations $F\left(\right.$ ) over $n_{T}$ discrete time steps and $n_{R}$ regions relating the state $B$ of the resource in a region $r$ at time $t+1$ to the state of this resource at time $t$, the human utilization $h$ of the resource and stochastic processes $\omega$ within time-step $t$ over $n_{T}$ time steps:

$$
B(r, t+1)=F(B(r, t), h(r, t), \omega(r, t)), \quad t \in T \equiv\left\{t_{1}, \ldots, t_{n_{T}}\right\}
$$

Equation 1

The state of the system in a region $r$ at time $t$ can be summarized by $K$ indicators, $\left\{I_{k}(r, t), k=\right.$ $1 \ldots K\}$, reflecting the different objectives which may be considered in assessing the performance of management strategies. Evaluation of management performance at any time step is assumed to account for both the status of the biological resource $B(r, t)$, and utility derived from utilization of the resource $h(r, t)$, with an evaluation function $G()$ such that:

$$
I_{k}(r, t)=G(B(r, t), h(r, t), \omega(r, t)), \quad r \in R \equiv\left\{1, \ldots, n_{R}\right\}, \quad t \in T \quad \text { Equation 2 }
$$

In general, the indicators should be calculable from the set of states $S$ :

$$
S=\{B(r, t) ; h(r, t) ; r \in R, t \in T\}
$$

Equation 3

implying that $S$, and consequently $F$ and $G$, must hold sufficient detail for the calculation to be performed. Note that, because the system is stochastic, so too are the indicators. 


\subsubsection{Definition of viability indices}

We define a viability threshold $\theta_{k}$ for indicator $I_{k}(r, t)$ such that, if the indicator falls below the threshold, the state of the region is deemed to be unviable. This is represented by the function $v\left(r, t, \theta_{k}, \omega\right)$ taking value 1 if the state is viable, otherwise 0 :

$$
v\left(r, t, \theta_{k}, \omega\right)= \begin{cases}1 & I_{k}(r, t) \geq \theta_{k} \\ 0 & I_{k}(r, t)<\theta_{k}\end{cases}
$$

Equation 4

Note that the argument $\omega$ is included to denote the stochastic dependence.

The local viability index for the region at time $t$ is defined as

$$
V(r, t, \theta, \omega)=\prod_{k=1}^{K} v\left(r, t, \theta_{k}, \omega\right)
$$

Equation 5

The index denotes the viability of the system on the smallest scale across all indicators, and also takes values of 0 or 1 .

At the scale of the entire resource system, we then define a regional viability index, $V_{R}(t, \theta, \omega)$. Let $g_{R}(\cdot)$ be a scalar-valued aggregation function taking a vector argument. Then

$$
V_{R}(t, \theta, \omega)=g_{R}(V(\cdot, t, \theta, \omega))
$$

Equation 6

where the aggregation is over spatial regions at a given time step. Examples of aggregation functions are min or max, in which case $V_{R}(t, \theta, \omega) \in\{0,1\}$, or mean, when $V_{R}(t, \theta, \omega) \in[0,1]$.

Indices can also be aggregated over time to provide a time- and space-independent, global index of viability

$$
V_{R T}(\theta, \omega)=f_{T}\left(V_{R}(\cdot, \theta, \omega)\right)
$$

Equation 7

where $f_{T}(\cdot)$ is a temporal aggregation function. This index represents viability on the largest scale, making it feasible to compare alternative management strategies, and so is of most interest to managers.

The choice of aggregation functions affects the strictness with which viability is defined. For instance, if $f_{T}=g_{R}=\min$, then $V_{R T}(\theta, \omega)=0$ unless all regions are viable all the time. On the other hand $f_{T}=g_{R}=$ mean (i.e. averaging over space and time) provides a definition that is less sensitive to the presence of a few non-viable regions at certain time steps. Quantile aggregation functions provide a compromise between min and mean: e.g. $g_{R}=$ quantile $_{0.1}$ implies the system is considered viable at time $t$ if fewer than $10 \%$ of regions are non-viable. A refinement, $g_{R}=$ mean $_{w}$ using a weighted average with weight vector $w$, allows the relative importance of regions to be accounted for. For example, $w$ could be proportional to the surface area of the region, or of the habitat useful to the biological resource included in the region. The aggregation functions need not be the same; for example $f_{T}=\min$ and $g_{R}=$ quantile $_{0.1}$ might be a reasonable choice in some circumstances. The choice $f_{T}=$ last (a special case of mean $_{w}$ where all the weight is on the final time step) is common in MSE analysis where the state of the system at the end of the simulation is often the focus of evaluation. Table 1 lists a selection of commonly encountered aggregation functions. In this study we limit attention to spatial aggregation based on the mean (arrived at during the stakeholder process) but expand on the customary end-of-simulation focus to include the two other forms of temporal aggregation. 
As stated above, the viability indices are stochastic. One of the purposes of MSE is to assess management strategies in the presence of such stochasticity. The simplest summary of viability that accounts for stochasticity is the expected viability, defined as

$$
\bar{V}(\theta)=E_{\omega}\left[V_{R T}(\theta, \omega)\right]
$$

Equation 8

where $E_{\omega}[\cdot]$ denotes expectation. Here, we focus on expected viability; however, other measures, such as the variance or inter-quartile range could also be of interest, since management options resulting in lower variance in viability (more certainty) often tend to be preferred. In cases where $V_{R T}(\theta, \omega) \in\{0,1\}$ (e.g. strict viability), $\bar{V}(\theta)$ is the probability that the viability thresholds will be met. In practice, equation 8 is intractable (unless the equations of the resource system are extremely simple) and so $\bar{V}(\theta)$ must usually be estimated by averaging over replicate Monte Carlo simulations.

\subsubsection{Numerical computation of viable management strategies}

The remarks in this section apply to both $V_{R T}(\theta, \omega)$ and $\bar{V}(\theta)$, so the simplified notation $V(\theta)$ is adopted.

\subsubsection{Single operational management objective}

Viability of a management strategy can be calculated for a single objective $k$ by examining $V\left(\theta_{k}\right)$ as a function of viability threshold $\theta_{k}$. In general, $V\left(\theta_{k}\right) \rightarrow 1$ as $\theta_{k} \rightarrow 0$, which implies that the objective is satisfied for low thresholds $\theta_{k}$, whereas $V\left(\theta_{k}\right) \rightarrow 0$ for sufficiently large, $\theta_{k} \rightarrow \infty$, implying that the objective is not met for sufficiently high values of $\theta_{k}$. The shape of $V\left(\theta_{k}\right)$ as $\theta_{k}$ increases indicates the sensitivity of the system to changes in the PI. These viability curves may be compared across different strategies, allowing them to be ranked. For instance, given two strategies $\mathrm{X}$ and $\mathrm{Y}$, if $V_{X}\left(\theta_{k}\right)>V_{Y}\left(\theta_{k}\right)$ for all $\theta_{k}$, we may conclude that strategy $\mathrm{X}$ is preferable to strategy $Y$, irrespective of the choice of threshold, in that strategy $X$ presents a higher chance of viability for all $\theta_{k}$. Moreover, a flat viability curve over a range of $\theta_{k}$ indicates that the choice of threshold over that range is not critical to the viability of the strategy.

In the following case study we use 100 Monte Carlo replicates to obtain the mean curve and envelope of $V\left(\theta_{k}\right)$ across a range of threshold $\theta_{k}$ values.

\subsubsection{Multiple operational management objectives}

If there are two operational management objectives, $k$ and $l$, viability becomes a function of two reference levels, $\theta_{k}$ and $\theta_{l}$, which may be represented as a surface. The surface is approximated by evaluating $V\left(\theta_{k}, \theta_{l}\right)$ on a finite set of points $\left(\theta_{k}, \theta_{l}\right)$ and then interpolating to a fine grid, which can be represented by contours of $V$. If the contours of strategy $Y$ lie between the origin (assuming the minimum threshold value is always 0 ) and those of strategy $X$, then again strategy $X$ dominates strategy $\mathrm{Y}$, which is equivalent to finding $V_{X}\left(\theta_{k}, \theta_{l}\right)>V_{Y}\left(\theta_{k}, \theta_{l}\right)$ for all $\left(\theta_{k}, \theta_{l}\right)$. Of course it may turn out that strategy $\mathrm{X}$ is more favorable to objective $k$, whereas strategy $\mathrm{Y}$ is more favorable to objective l; in this case the contours may cross so that neither strategy dominates for all $\left(\theta_{k}, \theta_{l}\right)$. Generally, however, the side-by-side comparison of strategies using contours of $V$ is time consuming and awkward.

The difficulty in comparing the viability of alternative management strategies increases as more objectives are considered. Nevertheless, a simplification that reduces the viability hyper-surface 
to a one-dimensional representation is available. If strategy $X$ dominates strategy $Y$, when $X$ "s contours enclose $Y$ "s, then equivalently, for each contour level $v$ of viability, strategy $\mathrm{X}$ has a larger area of viable choices (settings of $\theta$ ) than $\mathrm{Y}$. This suggests that we could compare strategies in the viability versus viable area space. This is a generalization of the single objective case where $V\left(\theta_{k}\right)$ is plotted against $\theta_{k}$, with $\theta_{k}$ reinterpreted as a measure of viable choices. Generalizing to any number of dimensions, define $A(v)$ to be the volume of threshold space that is viable at level $v$ :

$$
A(v)=\int_{V(\theta)>v} V(\theta) d \theta
$$

Equation 9

The analogue of the one-dimensional viability curve is then $v(A) v s A$, where $v(A)$ is the inverse of $A(v)$.

\subsubsection{Computational considerations}

In general, calculation of $V(\theta)$ requires the application of aggregation functions separately for every value of $\theta$. However, it is sometimes possible to use a numerical approximation that avoids recalculation. We give an example for a single objective captured by indicator $I(r, t)$ using aggregation functions $f_{T}=$ last and $g_{R}=$ mean. Let $\left\{r_{1}, r_{2}, \ldots, r_{n_{R}}\right\}$ be an ordering of the regions such that $I\left(r_{1}, t_{n_{T}}\right) \geq I\left(r_{2}, t_{n_{T}}\right) \geq \cdots \geq I\left(r_{n_{R}}, t_{n_{T}}\right)$, and define $\theta_{(j)}=I\left(r_{j}, t_{n_{T}}\right)$. Then it follows that $V\left(\theta_{(j)}\right)=r_{j} / n_{R}$. In cases where $\theta_{(j)}=\theta_{(k)}$ for $j<k$ then $V\left(\theta_{(j)}\right)=V\left(\theta_{(k)}\right)=r_{k} / n_{R}$. The resulting viability values $V\left(\theta_{(j)}\right)$, coupled with the known values $V(0)=1$ and $V(\infty)=0$, are finally interpolated onto a uniform grid of $\theta$ values. Thus, repeated applications of $g_{R}$ for each $\theta$ are replaced by simple sort and interpolation operations, which can be performed very efficiently.

Once $V(\theta)$ has been obtained on a regular grid of $\theta$ values, the function, $A(v)$ can be calculated. For a given $v, A(v)$ is approximated by counting the number of grid cells having $V(\theta)>v$. This can be implemented using a similar calculation as in the previous paragraph: for example, in two dimensions assuming the $\theta$ values are on a $n \times n$ grid, and the $n^{2}$ viability values are sorted thus $v_{1} \geq v_{2} \geq \cdots \geq v_{n^{2}}$, then $A\left(v_{j}\right)=j / n^{2}$ (with similar handling as before when $v_{j}=v_{k}$ ). This approximation is used in the following case study, with $n=10$ for two objectives and $n=5$ for three objectives. To facilitate calculation of $V(\theta)$, which involved computation on large amounts of data (1,544 regions, 19 years, 100 replicates, 8 strategies, $10^{2}$ or $5^{3}$ thresholds), this was performed in a high-end Oracle data base using SQL queries.

The approximation of $A(v)$ could be improved by interpolating $V(\theta)$ onto a finer grid. Such interpolation is helped by the fact that $V(\theta)$ is monotonically decreasing along each dimension, and therefore is fairly smooth. Techniques such as monotone regression could be used to perform the interpolation. However in our study the simpler approximation based on counting viable grid cell was adequate for comparing strategies.

\subsection{Application to results from a simulation model of recreational fishing in Ningaloo Marine Park}

We apply this general framework to the evaluation of simulated alternatives with respect to management of recreational fishing in Ningaloo Marine Park (Western Australia). The simulation model that was used to generate the projections is known as the Effects of Line Fishing Simulator (ELFSim; Little et al. 2007, Mapstone et al. 2008). ELFSim was developed for other coral reef 
fisheries but recently applied to Ningaloo reef (Little et al. 2011) to explore the effectiveness of current and prospective management arrangements under several possible future scenarios on spangled emperor (Lethrinus nebulosus). Spangled emperor is a primary targeted species in the Ningaloo Marine Park and Gascoyne Coast Bioregion and is used by the Department of Fisheries Western Australia (DoFWA) as an indicator species to monitor effects of fishing on the inshore demersal (0 to $250 \mathrm{~m}$ depth range) suite of scale fish species (Marriott et al. 2010, Marriott et al. 2012).

The model is a stochastic simulation model in which important sources of process uncertainty, relating to fish population dynamics and fishing effort allocation, are captured with Monte Carlo sampling. Fishing behavior exhibited by individual fishing vessels was simulated using an agentbased approach. ELFSim also included a meta-population dynamics model of the target species simulating its full life history (i.e., age, sex and size structure with a monthly time-step) for 1,544 spatial subpopulation units. Subpopulation units were arbitrarily delineated by 1 minute grid lines of latitude and longitude within areas of coral reef habitat of the Marine Park, as identified from seafloor maps. Larval exchange between subpopulation units was modeled using a distancebased dispersal model, which is consistent with hypotheses generated from recent analyses of DNA microsatellite markers for spangled emperor in the Marine Park (Berry et al. 2012). There was also assumed to be no adult movement between the subpopulation units. Although individuals generally demonstrate relatively high site fidelity throughout most of the year at Ningaloo (Moran et al. 1993) and elsewhere (Chateau and Wantiez 2008), more recent research suggests that adults migrate from inside the lagoon to form dense aggregations outside the Ningaloo Reef crest during the peak spawning season (September-November) (Marriott et al. 2012). It is unknown to what extent this phenomenon may have affected the ELFSim simulation results.

The ELFSim simulation model was calibrated using observed data for the period 1965-2007, with a projection period for simulated scenarios and management strategies from 2007-2025. Some aspects of model specification including scenarios and management strategies for simulation were identified from stakeholder workshops. Full details and results of this MSE study are provided in Little et al. (2011).

\subsubsection{Selection of management strategies to test}

Current management arrangements for Ningaloo Marine Park include a sanctuary zonation for $34 \%$ of the park as well as regulation of recreational use to ensure sustainability of the targeted marine resources (Western Australia Department of Conservation and Land Management 2005). Strategies were identified from workshops involving multiple stakeholders including representatives of recreational fishing, commercial fishing, charter fishing, and conservation groups, as well as scientists and management representatives (Little et al., 2011). The workshops involved open discussions on alternative management options, with the aim to identify a list of alternative strategies. The list included: (i) keeping the current arrangements in place, including the existing zoning of sanctuaries (Current); (ii) using a modified (Closure 1) or an increased (Closure 2) network of marine sanctuaries; (iii) banning shore-based fishing in sanctuaries because the sanctuaries currently preclude only boat-based fishing while allowing shore based fishing (No Inshore); (iv) allowing fishing effort to double in connection with projected increases in visitor numbers in the region (Double Effort); (v) implementing a total catch limit (Catch Limit); (vi) implementing an educational program (Education), which would be expected to reduce infringement into sanctuaries, and informally reducing the bag limit through the development of a catch and release plan; and (vii) implementing an enforcement program by having a monitoring vessel patrol the coast, to reduce fishing in the sanctuaries, and catches over the bag limit 
(Monitoring). A simulated Catch Limit strategy (viii) was also considered, despite the fact that capping the overall catch may not be practical for this fishery. In addition, the effectiveness of a catch limit strategy would be affected by the extent to which over-catching, high-grading and discarding occur. Such a strategy would also be species-specific, and therefore would not limit potential sustainability risks for other species, whose catch is not constrained, despite the use of spangled emperor as an indicator species for the suite of demersal scalefish species in the Gascoyne Coast Bioregion (Little et al. 2011, Marriott et al. 2012). Given these limitations, the strategy was included mainly as a reference, with which alternative and more realistic management options could be compared. In reality, management of recreational fishing typically involves a combination of regulations limiting fishing effort, although some novel methods to directly limit catches have also been implemented in Western Australia, such as the pink snapper tags used in the Freycinet Estuary in Shark Bay, WA, to limit total recreational catch from that area; see (Jackson and Moran 2012). For each of the management strategies examined, 100 replicates were simulated.

\subsubsection{Identification of operational management objectives by stakeholders}

The current management plan for the Ningaloo Marine Park is directed at conservation of a broad range of ecological and social values, including the protection of exploited fish species and communities, as well as the preservation of recreational values. Operational management objectives were specified in a series of workshops involving key stakeholders with an interest in the management of recreational fishing in the Park.

The identified objectives related to both conservation and social dimensions (Little et al. 2011). Discussions led to the identification of a set of candidate operational management objectives(Table 2). These included conservation objectives represented by the biomass of mature spangled emperor (hereafter referred to as "spawning biomass") in sanctuaries, outside sanctuaries, at the scale of the entire reef, and compared to un-fished levels. Discussions focused on what the reference levels should be for each of these PIs, with several possible values identified for some indicators, and a feeling expressed by participants that the choice of a level was arbitrary. For example, for the purpose of the evaluation produced as part of the project, participants agreed that the target reference level for spawning biomass in marine sanctuaries should be above either $75 \%$ or $90 \%$ of un-fished spawning biomass, while it should be above $40 \%$ of un-fished biomass at the scale of the entire reef. Other ecological management objectives involved the biomass available to recreational fishers, as well as the length and age distributions of the spangled emperor population. These candidate management objectives essentially specified that the age and length distribution of the population in the sanctuaries should approximate the age distribution of an unexploited population.

A social objective identified for the Ningaloo reef recreational fishery was that a good recreational fishing experience be maintained. This was captured operationally as the total (landed and discarded) catch rate should be greater in the future than the most recent values observed, and also that there should be a good chance of catching a trophy fish, defined as a fish greater than $50 \mathrm{~cm}$ in length. The reference chosen was that $25 \%$ of the catch should be of trophy fish (Table 2). This PI was required to meet its target by 2025 , with a tolerance of $75 \%$ of the time (i.e. in $75 / 100$ simulations). The arbitrary nature of these reference levels was again highlighted by workshop participants. In particular, participants stressed the fact that in practice different anglers might support different reference levels for the different objectives and that finding a way to work with such diversity of values would be important. Several other Pls were thought to be relevant, but could not be treated as performance measures for the purpose of MSE, as no clear reference levels for the corresponding PIs could be identified in the course of the workshops. Simulated 
values of these other Pls were, however, monitored as additional descriptors of the consequences of alternative management strategies in the output of the model runs. These included the number of days, or trips in which no fish are caught, the total landed catch, discards, and the variability in catch.

\subsubsection{Indicators}

In this study, the spatial unit or region is the reef. Let $S B(r, t)$ be the spawning biomass of spangled emperor and $B F(r, t)$ the proportion of „big fish" $(>50 \mathrm{~cm})$ caught, on reef $r$ in year $t$. Also denote by $t_{0}$ the time before exploitation commenced. We consider the following indicators, the value of which may only apply to reefs that are either closed or open to fishing:

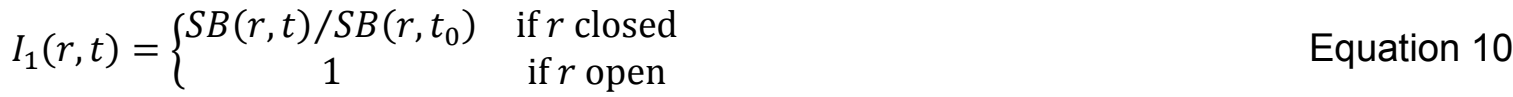

$$
\begin{aligned}
& \begin{array}{ll}
I_{2}(r, t)=S B(r, t) / S B\left(r, t_{0}\right) & \text { Equation } 11
\end{array}
\end{aligned}
$$

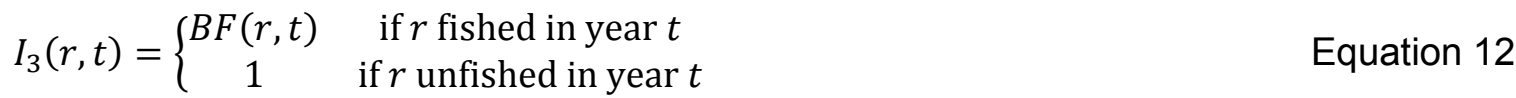

The first indicator relates to Objectives $1 \mathrm{a}$ and $1 \mathrm{~b}$ in Table 2, spawning biomass in sanctuaries; the second to Objective 2, spawning biomass across the entire reef; and the third to Objective 3, big fish catches for recreational fishing. Note that the indicators take value 1 for reefs that are not related to the objective; this is to ensure the calculation of reef viability $V(r, t, \theta, \omega)$ is not affected by irrelevant cases. From Table 2, the candidate reference levels identified from the stakeholder workshops were $\theta_{1}=0.75$ or $0.90, \theta_{2}=0.4$ and $\theta_{3}=0.25$. However, our analysis allows us to evaluate sensitivity of $V(r, t, \theta, \omega)$ to any values taken by these thresholds.

\section{Numerical results}

\subsection{Single operational management objective}

We initially focus on the effect of changing the reference level on the indicator of fish $>50 \mathrm{~cm}$ in the catch (objective 3 , see Table 2), hence use $I_{3}(r, t)$ as our viability indicator. In addition, we assume $f_{T}=$ last and $g_{R}=$ mean $_{w}$, where $w=1$ if the reef has been fished, otherwise 0 (see Table 1). The viability curves, shown in Figure 1 for each replicate run, all have the same basic shape: they begin at $(0,1)$, where there is effectively no constraint imposed, and decrease monotonically to $(1,0)$, where no reefs remain viable. As the reference level for the catch of large $>50 \mathrm{~cm}$ fish increases, viability decreases slowly for most strategies. This indicates there is some flexibility as to how to choose this threshold, provided it is not set too high. Moreover, some strategies (e.g. Catch Limit) display more flexibility than others (e.g. Double Effort). The mean curve for the Current strategy is overlaid on each panel to help compare the strategies. Current, Education and Monitoring are very similar with respect to this objective; the closure strategies and especially Double Effort allow less flexibility, whereas No Inshore and Catch Limit provide the most flexibility. The best and worst performing strategies (Catch Limit and Double Effort) are also the most variable (widest envelopes), indicating an increased uncertainty in the outcomes. Despite the clear ranking of strategies, all strategies nevertheless are viable with respect to the 
definitions set by the stakeholder group: all curves lie above the point $(0.4,0.75)$. If the stakeholders were in general agreement to set this threshold no higher than about 0.4 , then this objective would not put a serious constraint on the consideration of alternative strategies.

The effects of changing the reference level for the spawning biomass indicator $I_{2}$, is shown in Figure 2, using the same aggregation functions except that the mean is calculated over all reefs. In contrast to Figure 1, viability was computed by repeated aggregation over a grid of values $\theta_{2}=0,0.1, \ldots, 1.0$, so that the curves are less smooth. Several of the management strategies do not meet the objective, including the Current strategy. The objective could be met by the Current strategy by reducing the tolerance $V_{\text {lim }}$ to $70 \%$, or reducing the threshold $\theta_{2}$ from the $40 \%$ of initial spawning biomass (Table 2) to $30 \%$. The impact of changes in the threshold on the viability of management strategies appears greater in this case (due to many reefs being strongly depleted, i.e. with small values of $I_{2}$ ). This objective is strongly constraining and would focus attention on strategies giving more room to maneuver: No Inshore and Catch Limit. Under the nominal conditions set by the stakeholder group, these appear to be the only viable strategies (noting however the limitations already highlighted with respect to effective applicability of the Catch Limit strategy).

\subsection{Two operational management objectives}

The stakeholder group set tolerances for each objective in isolation. However, it is desirable to find strategies that meet all objectives simultaneously, and to assess the sensitivity of this to the threshold levels set for the different objectives. We therefore consider viability jointly, first for the two objectives discussed separately above. We compute the joint expected viability $\bar{V}\left(\theta_{2}, \theta_{3}\right)$ on a $10 \times 10$ grid of values of $\left(\theta_{2}, \theta_{3}\right)$ averaged over all 100 runs using the same aggregation functions as for the last example (Figure 3 ).

The surface in each panel shows the relation between reference levels for the two indicators. We have not attempted to represent the variation across runs. Nevertheless, we can see that the Catch Limit strategy dominates all others (its contours envelop those of all other strategies). With a requirement that both indicators meet their reference level with a probability of $75 \%$, only the Catch Limit strategy appears jointly viable with respect to both objectives (red cross lies inside the 0.75 contour). This is the only strategy that is viable according to the stakeholder definition. For the No Inshore strategy at least $75 \%$ of reefs were viable for each objective separately, but they were not all the same reefs; hence only $70 \%$ of reefs satisfied both objectives. Thus, with the aggregation functions used here, the No Inshore strategy would appear viable if the tolerance was reduced to $70 \%$ or less.

The strategies can also be compared by plotting viability against the viability volume $A$. As stated in section 2.1.2.3., we used a simple and crude approach by approximating $A(v)$ as the proportion of gridded values with $V>v$ (Figure 4). The stepwise character of the resulting curves (Figure 4) is a consequence of this approximation. Figure 4(a) shows the result for 2025; the Double Effort, No Inshore and Catch Limit strategies stand out as before, and the other strategies are grouped together.

In Figure 4(c), we consider a stricter definition of viability, where the minimum viability over all time steps is used. While the previous definition lends importance to the future only (as only the state of Ningaloo Reef in the final simulated year is considered), this definition of strong viability 
imposes that constraints be met in all years. Naturally the extent to which all strategies can be viable is reduced under this definition. Moreover, the Catch Limit strategy appears to be much less favorable than No Inshore, becoming comparable to most of the other strategies. This is because under the Catch Limit strategy, viability constraints are not met in the early time steps of the projections. This illustrates the importance that the transient performance of a strategy may have when assessing its viability.

A compromise definition of viability using the average over years is shown in Figure $4(b)$. This definition, which we call weak viability, measures the degree to which viability is sustained over the future projection; less viable transient stages are not penalized as harshly as under the strong definition. Both Catch Limit and No Inshore remain relatively favorable and fairly similar, with the narrowing of the margin relative to the ,future" definition of viability arising because of the poorer performance of Catch Limit in the earlier years.

\subsection{More than two operational management objectives}

We computed the ability of the management strategies to achieve all ecological and social management objectives, i.e. (Table 2) restoring spawning biomass in sanctuaries, restoring spawning biomass across the entire reef and maintaining catch of trophy fish (using the joint expected viability $\bar{V}\left(\theta_{1}, \theta_{2}, \theta_{3}\right)$ on a $5 \times 5 \times 5$ grid of values of $\left(\theta_{1}, \theta_{2}, \theta_{3}\right)$. Increased computational demands meant these results are based on only 9 simulations. Using the same three definitions of viability as for the two-dimensional case, the average curves are plotted together in Figure 5. The curves provide a similar ranking of the strategies as before. However, some more detail emerges as the two closure strategies appear to be less flexible than the Current, Education and Monitoring strategies. In contrast to Figure 4, the Catch Limit strategy appears to be the most favorable under all definitions of viability.

\section{Discussion}

A set of operational objectives for Ningaloo Reef (WA) was developed with stakeholders as part of a research project aimed at exploring the potential effects of alternative options to manage recreational fishing in the region using a computer model (Little et al., 2011). In this process, elucidating operational objectives from different stakeholder groups led to the identification of multiple indicators and proposed reference and tolerance levels (Little et al. 2011), an outcome which has been similarly seen in other such studies (Mapstone et al. 2008, Holland 2010). This subsequently led to a highly multi-dimensional set of simulation results from the MSE model: across strategies, scenarios, replicate runs and operational objectives.

We propose an approach to the evaluation of management strategies in such applications which allows dealing with both the high number of dimensions encountered, and the existence of a degree of uncertainty as to particular targets which should be pursued in each of these dimensions. The approach involves the application of viability analysis to the simulation outputs describing potential future ecological and socio-economic states of the resource system under consideration. A viability index is calculated for each strategy for comparing and contrasting across strategies.

Our results show that this approach offers a powerful way of synthesizing the outcomes of a large set of simulation runs, while also allowing us to assess the potential sensitivity of the results to individual target values identified by stakeholders in the course of developing the simulation plan. 
This approach is likely to be relevant to a broad range of MSE applications where similar issues in specifying operational management objectives are encountered, due to uncertainty in the ecological and/or socio-economic thresholds which should be applied, and the existence of multiple perceptions of what these thresholds are.

For the application of the ELFsim MSE model to recreational fishing of spangled emperor in the Ningaloo Marine Park, it appears that the objectives that most constrained viability of the simulated management strategies related to the preservation of spawning biomass. On the other hand, the objective related to preserving the quality of the recreational fishing experience (i.e., $\theta_{3}$ : proportion of fish $>50 \mathrm{~cm}$ ) was relatively non-constraining if the reference levels used were a good reflection of the expectations of all stakeholders. This implies that uncertainty and/or disagreement relating to the setting of reference levels for spawning biomass recovery is likely to have strong consequences in terms of the identification of viable management strategies ${ }^{1}$.

Our re-analysis of the simulation results of Little et al. (2011) also showed that there were two strategies that provided greater "room to move" in setting reference and tolerance levels for the range of objectives identified by stakeholders. These were the No Inshore management strategy, which was identified as a strategy that could be implemented in practice, and the Catch Limit management strategy, which was included as a reference in the simulations for comparison purposes, but has less practical applicability. Both strategies dominated all the others within the broader viability domain shaped by the ELFsim MSE model. However, the extent to which this was observed depended on the strictness with which viability of the management strategies was assessed. In the strong viability case, where the constraints must be met in all years of the simulation, there were fewer win-win strategies than in the weak viability case or the 2025 viability case. This is because the transitional path followed by each strategy in most cases is not able to meet the constraints as they were defined by stakeholders in the workshops, although the system does meet these constraints by the end of the simulated time series. This illustrates the trade-offs associated to the timing of recovery efforts for a renewable resource, which have also been analyzed using viability analysis (Martinet et al. 2007).

As explained in section 2, the discussion among stakeholders around setting targets for the reference points also involved the question of pre-agreed tolerance levels on these objectives. That is, stakeholders might be willing to specify stricter targets with looser tolerances, in terms of the proportion of time the targets are met. Our approach allows computing such trade-offs. An example is shown in Figure 3 for the No Inshore strategy. The blue circle indicates the point on the viability that minimizes the distance on the viability surface from the ideal (but unattainable) point $\left(\theta_{2}, \theta_{3}\right)=(1,1)$ and $\bar{V}=1$. The motivation of this is that it represents the best compromise between relaxing the thresholds and sacrificing viability, as measured by simple Euclidean distance. This heuristic setting could form the starting point of a discussion between stakeholders around reference level and tolerance setting. In the case represented here, the fact that some strategies (Catch Limit, No Inshore) allow for higher tolerance levels with stricter targets again shows that these strategies would appear to provide more flexibility in defining operational

\footnotetext{
1 An alternative approach could involve the identification of a value function measuring the benefits associated with alternative management strategies. For example, alternative strategies for the management of recreational fishing in Ningaloo Marine Park may be associated with different levels of economic profits for the industries supporting recreational fishing, or with different levels of consumer surplus for recreational fishers. This could enable the identification of those strategies which provide the highest overall value for a set of operational objectives, as has been done, for example, in applications of viability analysis to the management of mixed fisheries (Gourguet et al. 2013), but was beyond the scope of the application presented here.
} 
objectives. However, the tolerance achieved is lower than the default $75 \%$ which were adopted for all objectives in the workshops. Achieving such tolerance levels would require significant reduction in the target reference level ambition for the spawning biomass objective, although the extent of the reduction needed varies according to the strategy.

In this application heavy computing resources were needed to carry out the computations on the fairly large data sets generated by the simulation model. These experiences may be useful as a guide to researchers wishing to apply this viability approach to other studies. The magnitude of the computation depends on the number of spatial units, temporal units, replicates, strategies and indicators. In our case the limiting factor was the large number $(1,544)$ of spatial subpopulation units. In general, using fewer subpopulation units, with viability defined at a more aggregated level, would substantially ease the computational burden. The same is true when only a single time-point is needed (usually the end of simulation). For deterministic models a further substantial saving is afforded, since replication becomes unnecessary.

Whereas the number of spatial or temporal units (e.g. months in this example) may be large, the number of indicators must necessarily be small, perhaps no greater than 5 . This is partly constrained by computational demands (as seen in this study), but mainly by considerations of practicality. The "curse of dimensionality" applies to our ability both to compute viability and to conceive of it. A practical way to reduce the number of indicators to consider jointly would be to identify those that are weakly constraining (e.g. using pairwise contour plots as in Figure 3 ) and eliminate them in favour of the strongly-constraining indicators.

A further technical consideration is the spatio-temporal aggregation. Applying this in two stages, over space followed by time, as in this study, is usually computationally feasible. However some types of aggregation (e.g. the median over all space and time) require all the data to be in memory and so may not be possible to compute.

\section{Conclusion}

Management strategies for renewable resource systems should explicitly consider contested objectives from different stakeholders. Effective decision-making requires a degree of stakeholder engagement to help define relevant operational objectives, strategies and scenarios. Simulation using MSE can then be used to determine the likelihood of the strategies in achieving the objectives. Ways to synthesize the anticipated results of alternative strategy evaluations and to assess the sensitivity of these results to the reference and tolerance levels are strongly required. The approach proposed here involves the application of viability analysis, and developing a set of viability indices which can be used to summarize the information from simulation model outputs in a compact way. It can also be used to determine whether some strategies provide greater room to move in setting reference levels. Beyond the current application to Ningaloo Reef, this approach could be transferrable to any other simulation-based outcomes of MSE for natural resource systems, both marine and land-based. Given the fast growing amount of research carried out in this domain, it is expected that methods such as the one proposed here will find increasing applications, to assist in making outputs more readily interpretable for decision support. 


\section{Acknowledgements}

This research benefited from the results of the project entitled "An evaluation of Management Strategies for Line Fishing in the Ningaloo Marine Park" for the Ningaloo Reef Project, component 3.2.3 on Biodiversity Assessment, Ecosystem Impacts of Human Usage and Management Strategy Evaluation. The research was supported by CSIRO"s Sustainable ocean ecosystems and living resources theme of the Wealth from Oceans research flagship. The authors are grateful to Tony Smith, Anastasios Xepapadeas, Brent Wise, Alex Hesp, Peter Stephenson, Karina Ryan and Lindsay Joll for useful comments on preliminary versions of the manuscript, and to two anonymous reviewers for constructive criticism.

\section{Literature cited}

Béné, C., L. Doyen, and D. Gabay. 2001. A viability analysis for a bio-economic model. Ecological Economics 36:385-396.

Berry, O., P. England, R. J. Marriott, C. Burridge, and S. J. Newman. 2012. Understanding agespecific dispersal in fishes through hydrodynamic modelling, genetic simulations and microsatellite DNA analysis. Molecular Ecology 21:2145-2159.

Boschetti, F., A. de La Tour, E. A. Fulton, and L. R. Little. 2010. Interactive modelling for natural resource management. Environmental Modelling \& Software 25:1075-1085.

Boschetti, F., C. Richert, I. Walker, J. Price, and L. Dutra. 2012. Assessing attitudes and cognitive styles of stakeholders in environmental projects involving computer modelling. Ecological Modelling 247:98-111.

Bunnefeld, N., E. Hoshino, and E. J. Milner-Gulland. 2011. Management strategy evaluation: a powerful tool for conservation? Trends in ecology \& evolution (Personal edition).

Butterworth, D. S., N. Bentley, J. A. A. De Oliveira, G. P. Donovan, L. T. Kell, A. M. Parma, A. E. Punt, K. J. Sainsbury, A. D. M. Smith, and T. K. Stokes. 2010. Purported flaws in management strategy evaluation: basic problems or misinterpretations? ICES Journal of Marine Science: Journal du Conseil.

Chateau, O. and L. Wantiez. 2008. Human impacts on residency behaviour of spangled emperor, Lethrinus nebulosus, in a marine protected area, as determined by acoustic telemetry. Journal of the Marine Biological Association of the United Kingdom 88:825-829.

d'Aquino, P., C. Le Page, F. Bousquet, and A. Bah. 2002. A novel mediating participatory modelling: the self-design process to accompany collective decision making. International Journal of Agricultural Resources, Governance and Ecology 2:59-74.

De Lara, M., L. Doyen, T. Guilbaud, and M.-J. Rochet. 2007. Is a management framework based on spawning-stock biomass indicators sustainable? A viability approach. ICES Journal of Marine Science: Journal du Conseil 64:761-767.

Dichmont, C. M., A. Deng, A. E. Punt, N. Ellis, W. N. Venables, T. Kompas, Y. Ye, S. Zhou, and J. Bishop. 2008. Beyond biological performance measures in management strategy evaluation: Bringing in economics and the effects of trawling on the benthos. Fisheries Research 94:238-250.

Dichmont, C. M., S. Pascoe, T. Kompas, A. E. Punt, and R. Deng. 2010. On implementing maximum economic yield in commercial fisheries. Proceedings of the National Academy of Sciences 107:16-21.

Doyen, L., O. Thebaud, C. Bene, V. Martinet, S. Gourguet, M. Bertignac, S. Fifas, and F. Blanchard. 2012. A stochastic viability approach to ecosystem-based fisheries management. Ecological Economics 75:32-42.

Eisenack, K., J. Scheffran, and J. P. Kropp. 2006. Viability analysis of management frameworks for fisheries. Environmental Modeling \& Assessment 11:69-79. 
Gourguet, S., C. Macher, L. Doyen, O. Thébaud, M. Bertignac, and O. Guyader. 2013. Managing mixed fisheries for bio-economic viability. Fisheries Research 140:46-62.

Hare, M., R. A. Letcher, and A. J. Jakeman. 2003. Participatory Modelling in Natural Resource Management: A Comparison of Four Case Studies. Integrated Assessment 4:62-72.

Holland, D. 2010. Management Strategy Evaluation and Management Procedures: Tools for Rebuilding and Sustaining Fisheries. Paris.

Jackson, G. and M. Moran. 2012. Recovery of inner Shark Bay snapper (Pagrus auratus) stocks: relevant research and adaptive recreational fisheries management in a World Heritage Property. Marine and Freshwater Research 63:1180-1190.

Jones, A., S. J. Slade, A. J. Williams, B. D. Mapstone, and K. J. Kane. 2007. Pitfalls and benefits of involving industry in fisheries research: A case study of the live reef fish industry in Queensland, Australia. Ocean \&amp; Coastal Management 50:428-442.

Little, L. R., O. Thébaud, F. Boschetti, A. D. McDonald, R. Marriott, B. Wise, and R. Lenanton. 2011. An Evaluation of Management Strategies for Line Fishing in the Ningaloo Marine Park. Final Report for Ningaloo Reef Project 3.2.3 Biodiversity Assessment, Ecosystem Impacts of Human Usage and Management Strategy Evaluation., CSIRO, Hobart.

Mapstone, B. D., L. R. Little, A. E. Punt, C. R. Davies, A. D. M. Smith, F. Pantus, A. D. McDonald, A. J. Williams, and A. Jones. 2008. Management strategy evaluation for line fishing in the Great Barrier Reef: Balancing conservation and multi-sector fishery objectives. Fisheries Research 94:315-329.

Marriott, R. J., D. J. Adams, N. D. C. Jarvis, M. J. Moran, S. J. Newman, and M. Craine. 2010. Age-based demographic assessment of fished stocks of Lethrinus nebulosus in the Gascoyne Bioregion of Western Australia. Fisheries Management and Ecology.

Marriott, R. J., G. Jackson, R. Lenanton, C. Telfer, E. Lai, P. Stephenson, C. Bruce, D. Adams, and J. Norriss. 2012. Biology and stock status of inshore demersal scalefish indicator species in the Gascoyne Coast Bioregion., Department of Fisheries, Western Australia.

Martinet, V., O. Thébaud, and L. Doyen. 2007. Defining viable recovery paths toward sustainable fisheries. Ecological Economics 64:411-422.

Moran, M., J. Edmonds, J. Jenke, G. Cassels, and C. Burton. 1993. Fisheries biology of emperors (Lethrinidae) in North-West Australian coastal waters., Department of Fisheries, Western Australia.

Pereau, J.-C., L. Doyen, L. R. Little, and O. Thebaud. 2012. The triple bottom line: Meeting ecological, economic and social goals with individual transferable quotas. Journal of Environmental Economics and Management 63:419-434.

Sainsbury, K. J., A. E. Punt, and A. D. M. Smith. 2000. Design of operational management strategies for achieving fishery ecosystem objectives. ICES Journal of Marine Science 57:731-741.

Smith, A. D. M. 1994. Management strategy evaluation: the light on the hill. Pages 249-253 in D. A. Hancock, editor. Population Dynamics for Fisheries Management. Australian Society for Fish Biology, Perth, Western Australia.

Smith, A. D. M., E. J. Fulton, A. J. Hobday, D. C. Smith, and P. Shoulder. 2007. Scientific tools to support the practical implementation of ecosystem-based fisheries management. ICES Journal of Marine Science: Journal du Conseil 64:633-639.

Voinov, A. and E. J. B. Gaddis. 2008. Lessons for successful participatory watershed modeling: A perspective from modeling practitioners. Ecological Modelling 216:197-207.

Western Australia Department of Conservation and Land Management, M. P. a. R. A. 2005. Management plan for the Ningaloo Marine Park and Muiron Islands Marine Management Area, 2005-2015. Fremantle, W.A. 


\section{Tables}

Table 1 - Aggregation functions of a vector of states (in time or space) $x=\left(x_{1}, x_{2}, \ldots x_{N}\right)$. The order statistics $x_{(i)}$ are the sorted values of $x$ in increasing order: $x_{(1)} \leq x_{(2)} \leq \cdots \leq x_{N}$

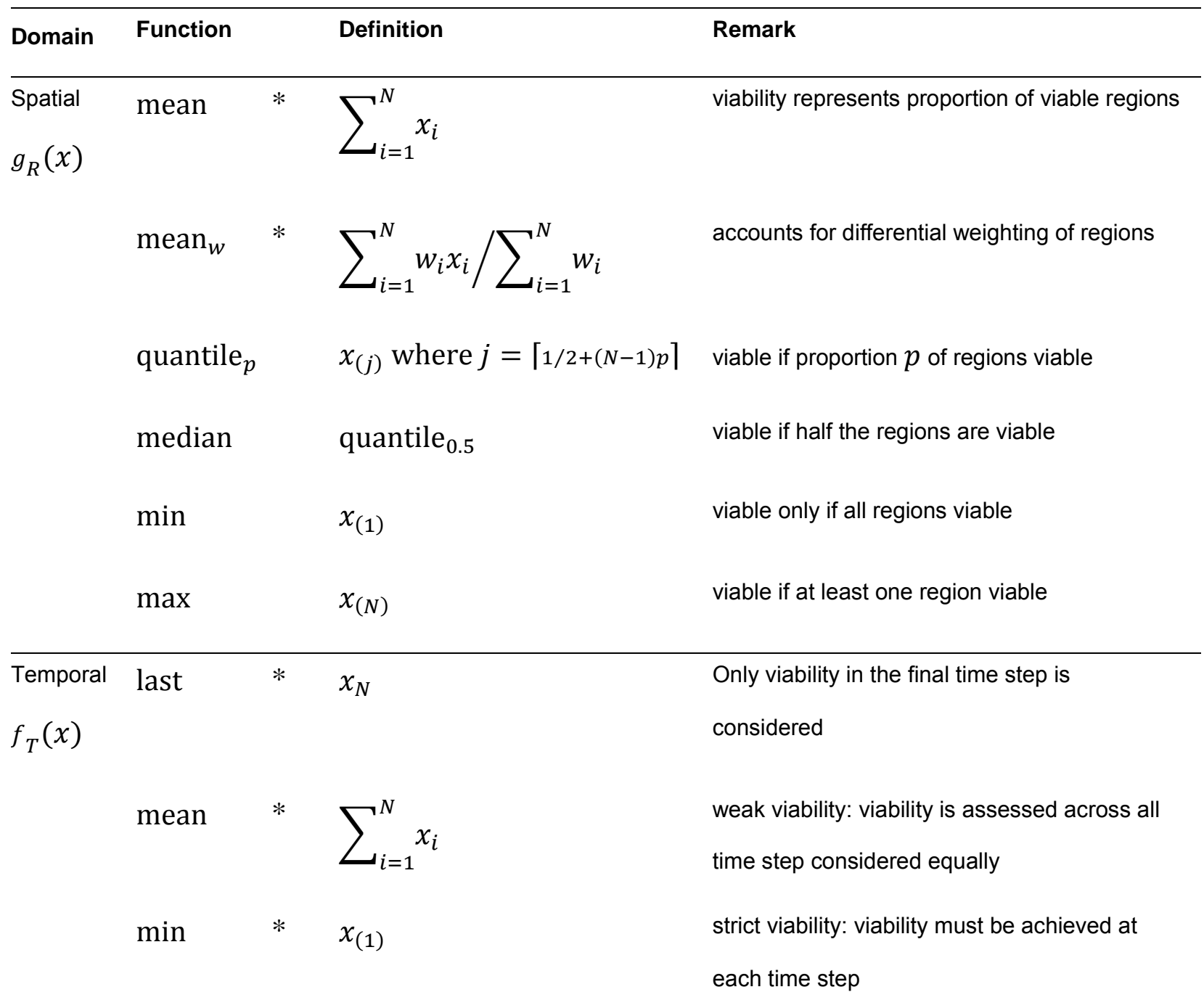

*Aggregation functions used in the analyses presented in section 3. 
Table 2 - Definition of operational management objectives for the recreational fishery in Ningaloo Marine Park for simulation modeling (from Little et al. 2011).

\begin{tabular}{clll}
\hline Objective $k$ & Indicator $I_{k}(r, t)$ & Threshold $\theta_{k}$ & Tolerance $V_{\lim }$ \\
\hline Ecological & & \\
1a & Spawning biomass in sanctuaries & $>90 \%$ unfished level & $75 \%$ of the time \\
1b & Spawning biomass in sanctuaries & $>75 \%$ unfished level $\quad 75 \%$ of the time \\
& & Spawning biomass across entire reef & $>40 \%$ unfished level $\quad 75 \%$ of the time
\end{tabular}

Social

3 Proportion of catch $>50 \mathrm{~cm} \quad 25 \%$ of total catch $75 \%$ of the time 
Figure 1 - Curves of $V_{R T}\left(\theta_{3}, \omega\right)$ vs $\theta_{3}$ over 100 replicates $\omega$ (grey lines) for each strategy considering indicator $I_{3}$ only. The aggregation functions are $f_{T}=$ last and $g_{R}=\operatorname{mean}_{w}$, where $w=$ 1 if the reef has been fished, otherwise 0 . For the Current strategy the mean relationship $\left(\bar{V}\left(\theta_{3}\right)\right)$ over all replicates is shown (dashed blue line). This line is duplicated in the panels for the other strategies to facilitate comparison. The vertical and horizontal dashed lines correspond to the nominal target ( $25 \%$ of catch) and tolerance ( $75 \%$ of reefs) set during stakeholder consultation (Table 2). According to this definition of viability, all simulated strategies are viable.

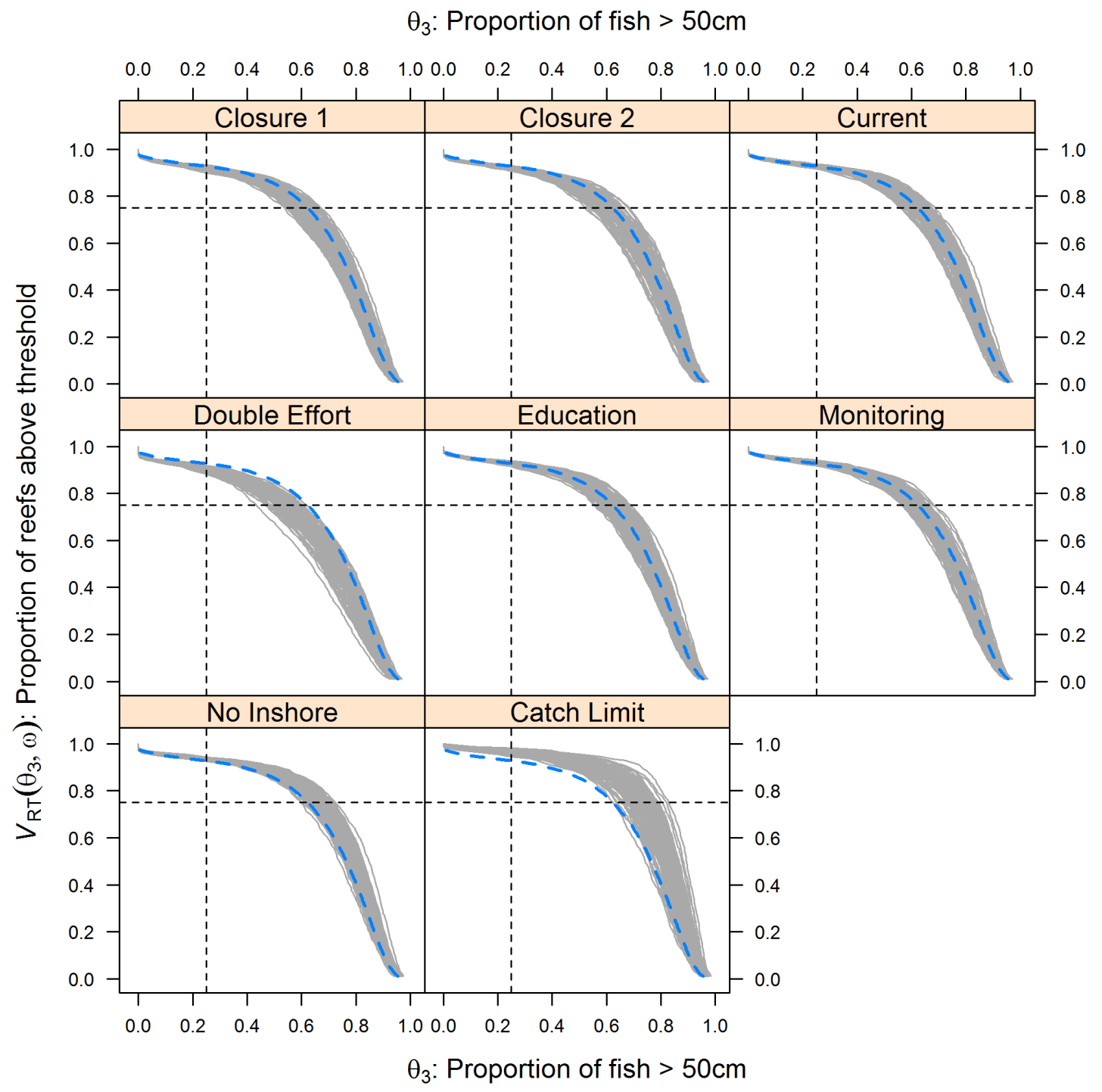


Figure 2 - Curves of $\boldsymbol{V}_{\boldsymbol{R}}\left(\boldsymbol{\theta}_{2}, \boldsymbol{\omega}\right)$ vs $\boldsymbol{\theta}_{2}$ over 100 replicates $\boldsymbol{\omega}$ (grey lines) for each strategy considering indicator $I_{2}$. The aggregation functions are $f_{T}=$ last and $g_{R}=$ mean. For the Current strategy the mean relationship $\left(\overline{\boldsymbol{V}}\left(\boldsymbol{\theta}_{2}\right)\right)$ over all replicates is shown (dashed blue line). This line is duplicated in the panels for the other strategies so that they can be compared. The vertical and horizontal dashed lines correspond to the nominal target (40\% of initial spawning biomass) and tolerance (75\% of reefs) set during stakeholder consultation (Table 2). According to this definition of viability, only the Catch Limit and No Inshore simulated strategies are viable.

$\theta_{2}$ : Spawning biomass/Initial spawning biomass

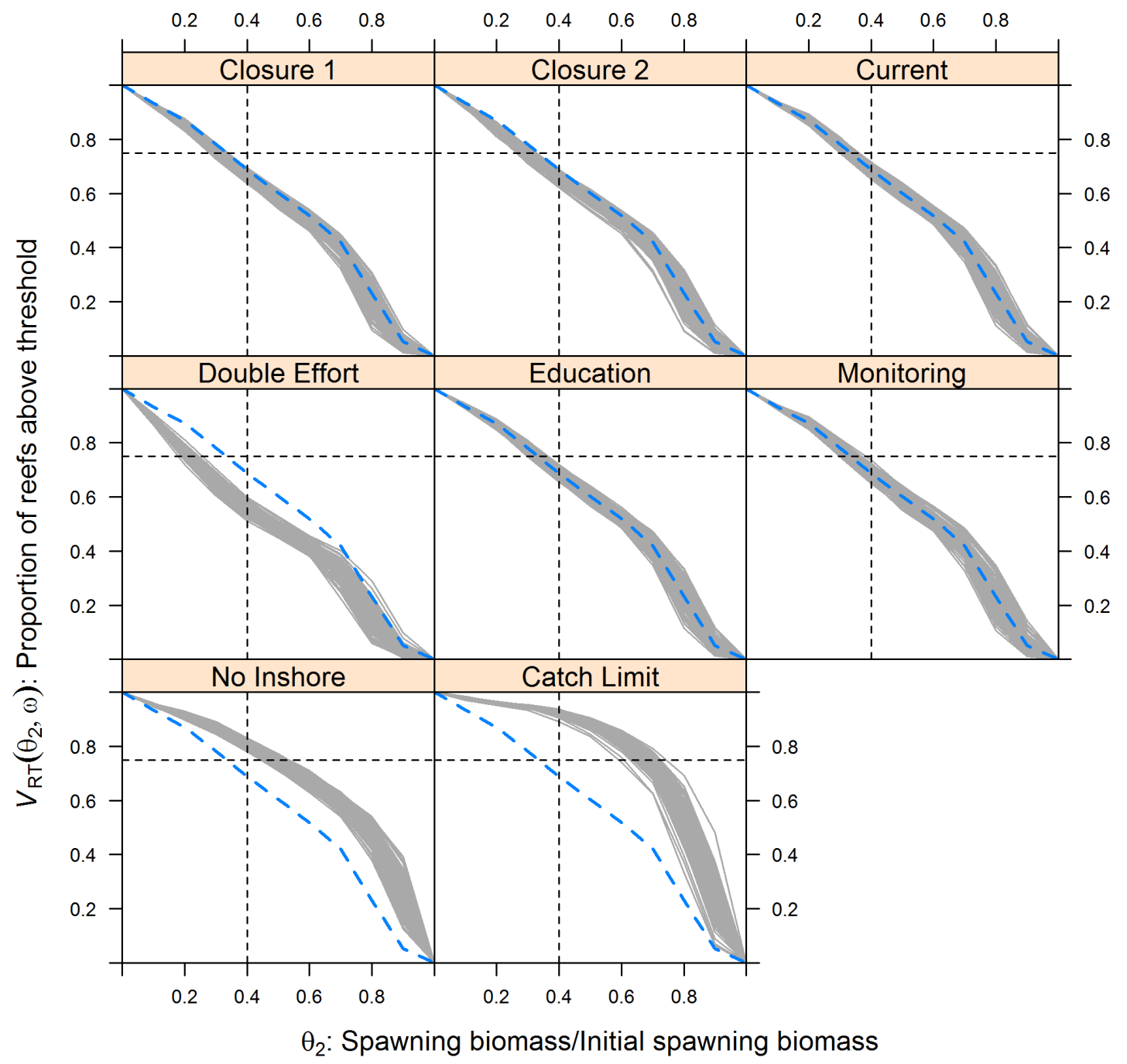


Figure 3 - The expected viability $\bar{V}\left(\theta_{2}, \theta_{3}\right)$ (estimated by averaging over 100 replicates), plotted as contours against $\theta_{2}$ and $\theta_{3}$. The aggregation functions are $f_{T}=$ last and $g_{R}=$ mean. The red cross denotes the nominal targets set during stakeholder consultation. The 0.75 contour is indicated by the dashed line. For the No Inshore case the blue circle represents the option that has minimal distance from the ideal case $\left(\theta_{2}, \theta_{3}, \bar{V}\right)=(1,1,1)$.

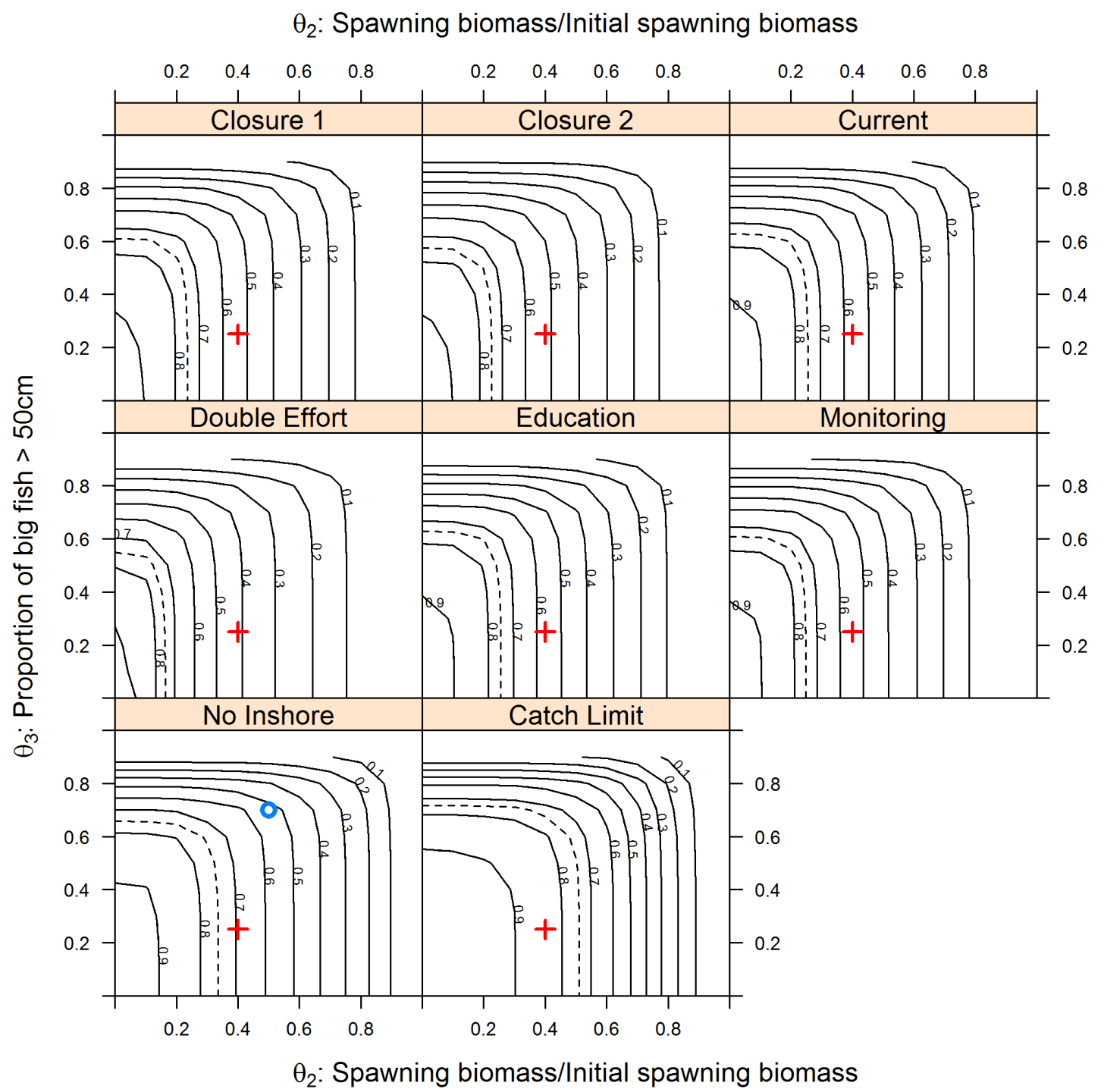


Figure 4 - The expected viability $\overline{\boldsymbol{V}}\left(\boldsymbol{\theta}_{2}, \boldsymbol{\theta}_{3}\right)$ (estimated by averaging over 100 replicates) plotted against viability hyper-volume. The aggregation functions are $\boldsymbol{g}_{\boldsymbol{R}}=$ mean and (a) $\boldsymbol{f}_{\boldsymbol{T}}=$ last - '2025 viability'; (b) $\boldsymbol{f}_{\boldsymbol{T}}=$ mean - weak viability; and (c) $\boldsymbol{f}_{T}=$ min - strong viability.

(a)

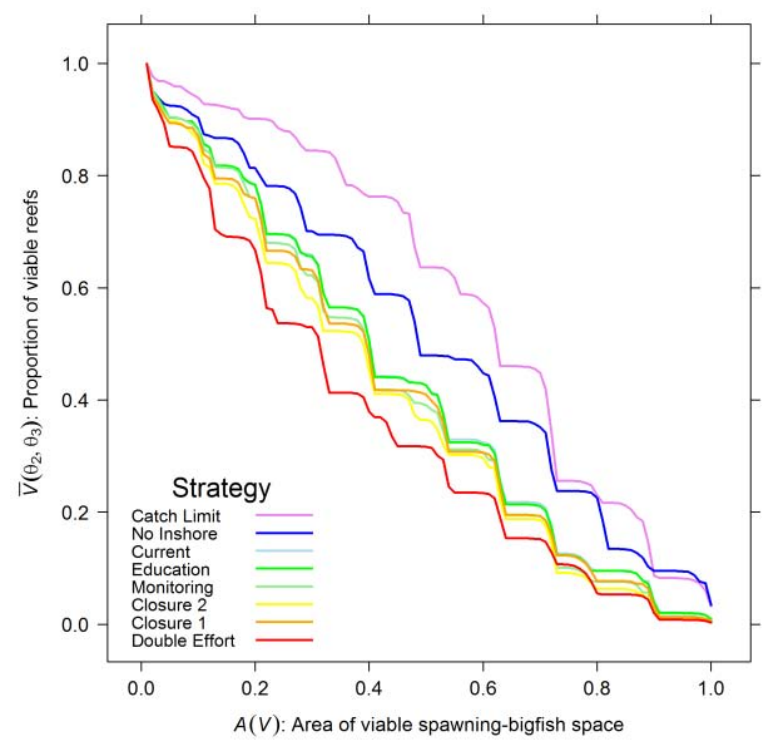

(b)

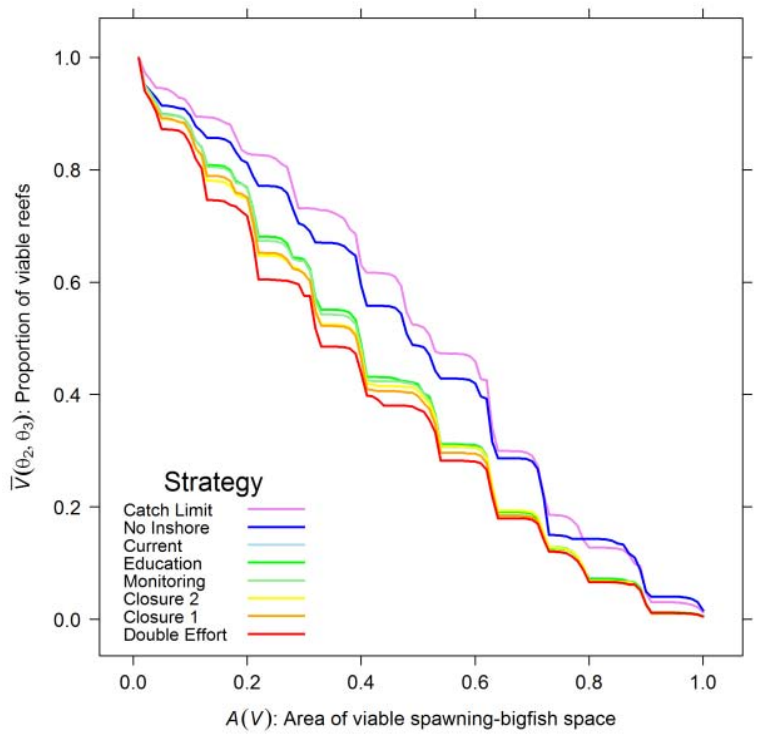

$(c)$

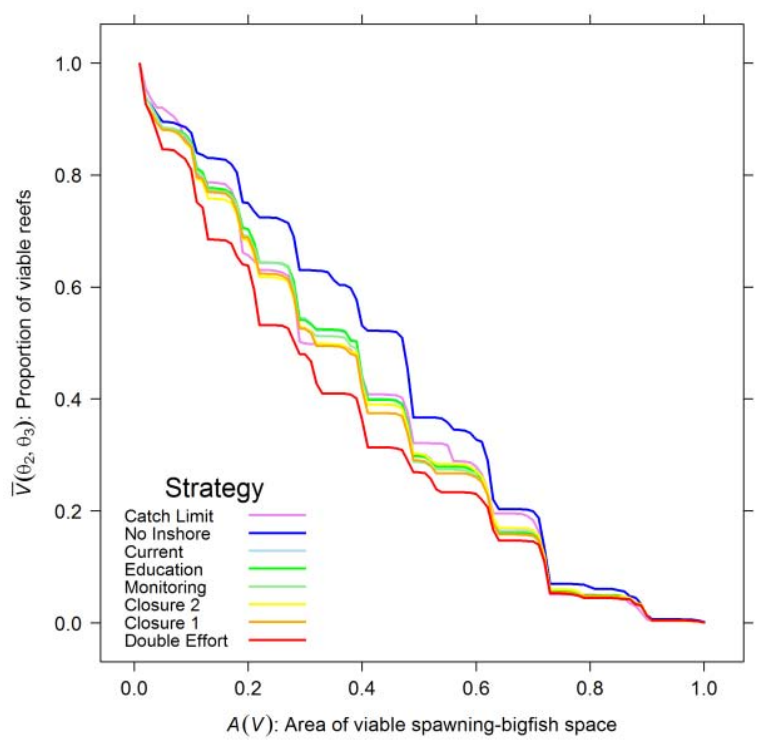


Figure 5 - The expected viability $\bar{V}\left(\theta_{1}, \theta_{2}, \theta_{3}\right)$ (estimated by averaging over 9 replicates) plotted against viability hyper-volume. The aggregation functions are $g_{R}=$ mean and (a) $f_{T}=$ last - '2025 viability'; (b) $f_{T}=$ mean - weak viability; and $(c) f_{T}=$ min - strong viability.

(a)

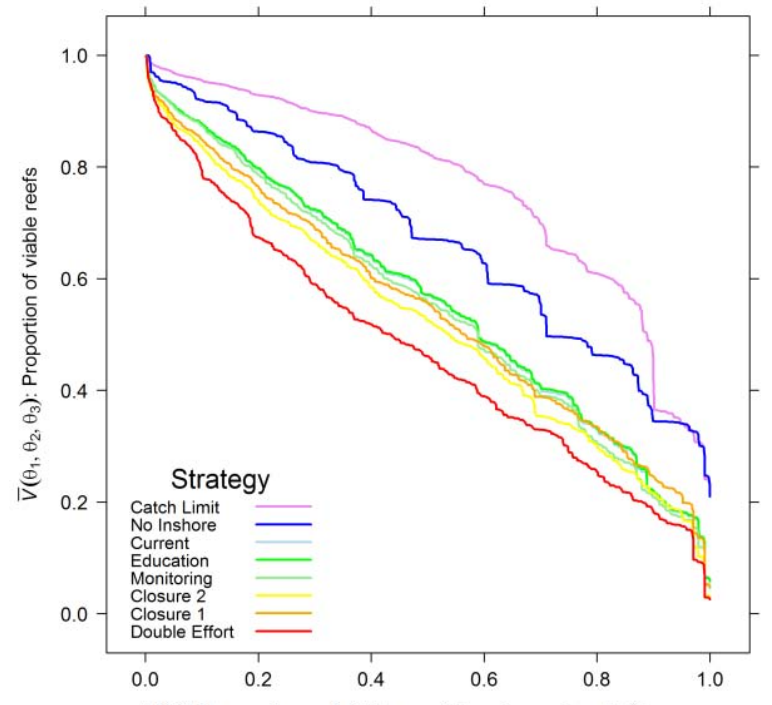

$A(V)$ : Hypervolume of viable open/closed spawning-bigfish space (b)

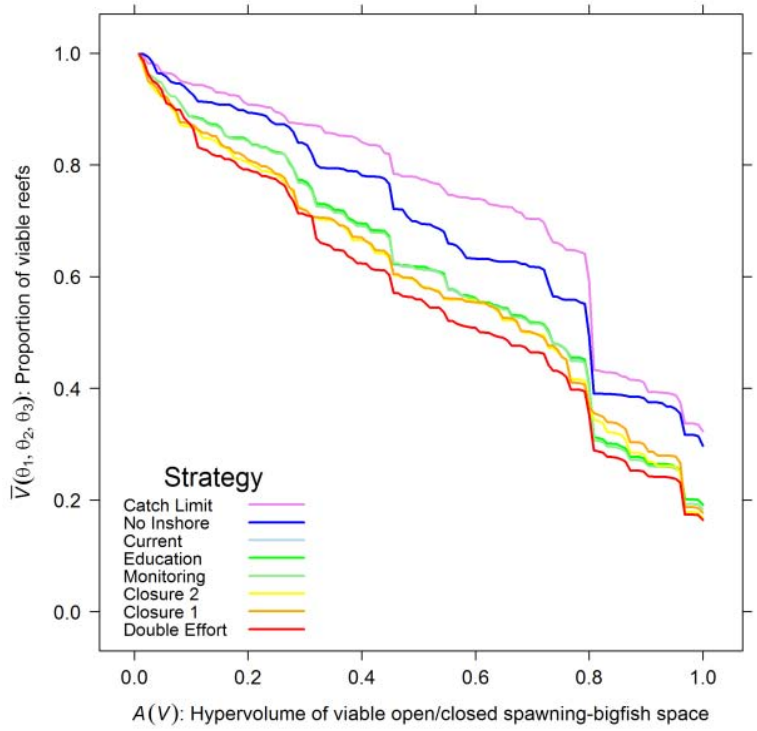

(c)

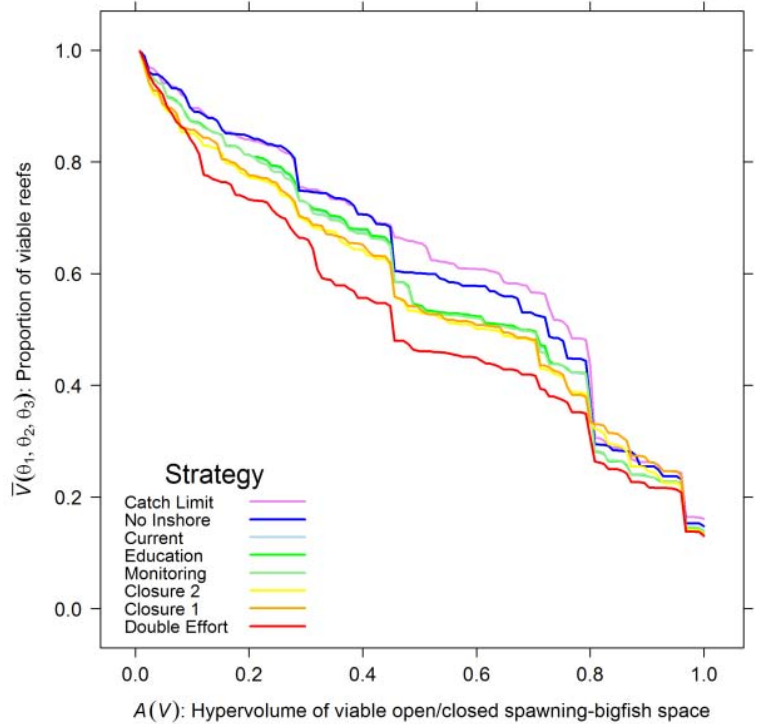

